\title{
Passions and Actions: Deleuze's Cinematographic Cogito
}

\author{
Richard Rushton Lancaster University
}

\begin{abstract}
When writing about cinema does Deleuze have a conception of cinema spectatorship? In New Philosophy for New Media, Mark Hansen argues that Deleuze does have a conception of cinema spectatorship but that the subjectivity central to that spectatorship is weak and impoverished. This article argues against Hansen's reductive interpretation of Deleuze. In doing so, it relies on the three syntheses of time developed in Difference and Repetition alongside an elaboration of Deleuze's notion of a 'cinematographic Cogito'. In this way, the article offers a way of understanding the processes of cinema spectatorship from a Deleuzian perspective.
\end{abstract}

Keywords: cinema, new media, spectatorship, interactive, Mark Hansen, Cogito

Although many agree that Deleuze's Cinema books $(1983,1985)$ are groundbreaking landmarks in the history of film studies, no-one seems quite sure what to do with them. A number of scholars have played the game of pitting the movement-image against the time-image in an attempt to display the superiorities of the latter, while others have gone to great lengths to demonstrate the ways in which Deleuze's approach to cinema dissolves the traditional notions of unified subjectivity that were the hallmarks of film theory in the 1970s and 1980s (see Pisters 2003; Olkowski 1999). However, very few have tried to work out who or what it is that engages with actual films from the Deleuzian perspective. From Deleuze's position, one might ask, are there spectators who go to see (and hear) films; which is to say, can we call the experience of watching (and listening to) a film an experience that belongs to or which is undergone by a subject? Given Deleuze's long-held suspicion of notions of subjectivity, such an assertion would appear to be highly 


\section{Richard Rushton}

problematic. But if it is not a subject who experiences a film, then who or what is it?

In New Philosophy for New Media (2004a), Mark Hansen claims that if there is a spectator of cinema for Deleuze, then this spectator is one who is wholly subjected to the cinema. For Hansen, if there is a loss of subjectivity in Deleuze's conception of a cinematic spectator, then this is because the spectator, while in front of a film, loses all of the defining characteristics of subjecthood. By way of contrast with Deleuze's cinematic spectator, Hansen claims that the subjects or spectators of new media maintain their subjecthood. As a process of creative interaction with new media artworks, the new media spectator forms part of an expanded subjectivity, whereby that subjectivity grows, is modified, and discovers new affectivities. I do not wish to take issue with Hansen's characterisation of new media subjectivities - that is not my field of speciality. But I certainly do want to question his understanding of Deleuze's cinematic spectator. The loss of subjecthood Deleuze's cinematic spectator experiences should not be construed as a negative; it is rather one of the powers of cinema. Indeed, such losses of subjecthood are precisely what characterise the Cogito specific to Deleuze's conception of cinema. Deleuze's cinematographic Cogito, as I argue below, can be most accurately charted by virtue of the three syntheses of time formulated in Difference and Repetition (1968). To my knowledge, the connection between the three syntheses and a cinematographic Cogito has not been made before, but I argue that this connection is essential to understanding Deleuze's approach to cinema and of who or what it is that has cinematic experiences.

\section{Against Deleuze: New Media Subjects}

What, then, is Hansen's argument? He puts forward an ingenious hypothesis: the significance of new media does not lie in the qualities of its objects, but rather in our responses to it. The specific qualities that make new media new have little or nothing to do with the properties of those media, and have everything to do with what they allow subjects - those who encounter new media objects - to achieve. If a spectator engages with a new media object then it is necessary for that spectator to interact with it in order for that object's true importance to emerge. New media are therefore interactive; they are defined less by what I receive from them than by what I can give to them. And according to Hansen's thesis, what I give to the objects of new media is affectivity. 
Affectivity, Hansen goes on to argue, is a bodily production of excess which occurs when the body breaks its boundaries and achieves something that it has hitherto been unable to or which it had never before had the chance to experience. Although Hansen does not mention video games, the example seems appropriate: when playing a video game I have the capacity to make things happen and therefore change the course of the game. In video games this is typically achieved by bodily manipulating controls - various buttons and joysticks - that involve genuinely new bodily skills, reflexes and motor co-ordinations, so that the body extends itself in order to respond to the game. Each new game brings with it the chance to produce new bodily skills. These are bodily affectivities, and furthermore, $I \mathrm{am}$ the one who makes these things happen; I am the one doing it. Rather than being solely at the mercy of a technology like cinema which, according to Hansen's argument, leaves me no room for manoeuvring or interacting, new media give me a role in their very coming-into-being. And my way of bringing about this coming-into-being is by creating the kinds of bodily affectivities that define what the new media experience is all about.

These activities also bring about a virtualisation of the body. It is as though, when playing a video game, I am stretched between the confines of my own bodily boundaries and the screen upon which the video game is displayed. There is thus a virtual body, partly mine, partly the video game's, a novel, hybrid body which is generated by me, my movements and activities, in the operation of bringing the video game into being. In other words, the game cannot exist without my being there to play it. There are thus two intertwined, essential qualities of new media: first, its potential to generate bodily affectivities which, second, imply a virtualisation of the body.

Hansen's prime examples of new media objects are not of video games, however, but of new media artworks. For example, he describes the effectiveness of Craig Kalpakjian's Hall as follows:

Hall (1999) is a continuous video loop of movement through a hall without any exits, which generates in the spectator a vertiginous feeling of being trapped in a deadly, because thoroughly generic, space. (Hansen 2004a: 210)

Hall can generate affectivities and virtualisations of the body because of the severe discrepancy between the human world in which the spectator is located and the technological world of the artwork. Because this work has no 'real world referent' there is no way for the spectator to relate to it in any straightforward way. There is a radical separation between the human-subject-spectator and the new media object. 


\section{Richard Rushton}

As such, there is no automatic connection between the subject and the object because new media objects act in ways that block, refuse, disjoint and confuse subjective responses. Human subjects are 'fundamentally excluded' (Hansen 2004a: 223) from the space of Hall, to the extent that Hansen describes these spaces as incompossible:

[T]his space is a radically nonhuman one, one without any analogical correlation to human movement and perception, and one into which affection can be introduced only from the outside, as a supplement that originates in the embodied response of the viewer-spectator. (Hansen 2004a: 215)

As a result of this radical disjunction between the human and nonhuman environments it is necessary for the spectator to generate something else: the spectator must generate affections or affectivities, which are, one could say, projected into or onto the artwork as a conjunction of spectator and work, as a consequence of the spectator's virtualisation of her/his body. The spectator's bodily affections must be virtualised in order for this artwork to come into being; the virtualised bodily affections are not produced by the artwork itself but only by what the spectator gives to the artwork.

Hansen moves the arguments surrounding new media away from an obsession with its objects. Instead of focussing on the aesthetic properties, the production aspects, the materials used, the digital programmes, or new media's 'virtual' nature, Hansen focuses on the ways we respond to and interact with such objects. New media objects have certainly assumed particular forms, but what is really special about them, for Hansen, is what they allow $u s$ to do.

Two main lines of argument are emphasised by Hansen. One line of argument highlights the nature of the virtual for new media, while a second centres on the notion of embodiment. First of all, the virtual is no longer seen as a property of new media: the significance of new media objects is not that they are virtual or that they create virtual realities, but rather that they make us virtual. Secondly, the realm of bits and digits and simulation does not make real bodies obsolete, for the body is central to Hansen's notion of new media. The notion of embodiment is essential because it is the body - through its affectivities and virtualisations - that produces a unique interaction with new media objects. For example, from Hansen's point of view - though, again, this is not an example he uses - the significance of Lara Croft (the digi-character from the video game, Tomb Raider) is not that she is an imaginary, simulated, impossible, non-existent, unrealisable body, but rather that such unrealisable-immaterial new media images open up new 
kinds of bodily processes for us. That is, digital images facilitate the production of new bodily affects.

\section{Old Media Subjects}

If new media are new, then what are the old media against which the newness of the new is measured? What exemplifies the old media for Hansen is cinema. It is cinema's treatment of the body and the virtual that are definitively different from new media. Taking his cues from Deleuze's Cinema books, Hansen argues that the significance of cinema is located entirely with its objects: films. Films function in such a way as to exclude any activities (or affectivities) of the spectator's body and they also foreclose the possibility of any virtualisation of the body. Why is this so? Films do this because their affectivities and virtualities are positioned entirely within films themselves. There is thus no room for interaction on the part of the film spectator: any affectivities or virtualisations are not a result of the spectator's interactions with a film; instead, they are wholly determined by that film. The film spectator can only passively mirror or receive the affectivities and virtualities that are produced by the film; the spectator's responses are fully determined by the film; the subject in front of the cinema screen is fully determined by the filmic object.

The distinctions between Hansen's new media theory and Deleuze's theory of cinema are therefore clear: the cinema, because it is in some way analogical, forms an intrinsic connection between the spectator's faculties of perception and the represented space of the film; any spectator is able to recognise and connect with (or 'identify' with, as traditional film theory would have it) the scenes and spaces depicted by a film. This then means that what a spectator perceives in the cinema is a represented space that is given to him/her; the spectator has to do nothing but receive the cinematic perceptions whose origins are external to the spectator-subject. The spectator, for his/her part, gives nothing to the cinematic object, for the perceptions of the cinema are external to this spectator.

For new media, according to Hansen's examples, the stakes are reversed. There is a distinct lack of connection between the spectator and the new media object and this lack of connection necessitates the fabricating of a connection on behalf of the spectator: the spectator must add to the new media object in order for its objecthood to come into being. Hence, it can be posited that, and this is the important point, the Deleuzian cinematic perceptions originate in the film-object, whereas Hansen's new media affectivities originate in the spectator-subject. 


\section{Richard Rushton}

Hansen's reading of Deleuze is inadequate. He makes Deleuze's film theory into a straw target by construing his work in such a way that it appears he gives everything over to the film-object. The reality, however, is that Deleuze's cinematic theory proposes a very original and somewhat complex interaction between the spectator and the screen, that is, between the spectator-subject and the film-object. I use the word interaction here deliberately: cinema is interactive. It is a composite of subject and object in which each determines, interrogates and investigates the other.

\section{Subjects and Objects in the Cinema}

What, then, might a Deleuzian response be? Where are the subjects and objects of cinema for him?

Minimally, it can be acknowledged that Deleuze at least makes the claim that there are subjective, point-of-view shots in the cinema; that is, the kinds of shots that are supposed to be from a particular character's point-of-view such that they depict what that character sees. But such shots cannot be divorced from the opposite kinds of shots: objective shots. These are shots which are from the objective eye of no-one the camera's eye-rather than that of a particular character. As Deleuze argues, even if we see a subjective shot, the only way we can know it is subjective is by way of its emplacement within an objective system of shots. 'A character acts on the screen', he writes, 'and is assumed to see the world in a certain way. But simultaneously the camera sees him, and sees his world, from another point of view which thinks, reflects, and transforms the viewpoint of the character' (Deleuze 1986: 74). In other words, a subjective shot is not merely a subjective shot; it can only be designated as subjective in relation to other, objective shots.

This may not appear to be a particularly profound point to make, except that Deleuze links this observation to what he calls a 'cinematographic Cogito':

Can we not find this dividing-in-two, or this differentiation of the subject in language, in thought and in art? It is the Cogito: an empirical subject cannot be born into the world without simultaneously being reflected in a transcendental subject which thinks it and in which it thinks itself. And the Cogito of art: there is no subject which acts without another which watches it act, and which grasps it as acted, itself assuming the freedom of which it deprives the former. (Deleuze 1986: 73) 
These lines from Cinema 1 are located amid a discussion of free indirect discourse in the cinema and are explicitly related to the philosophical notion of the Cogito developed by Henri Bergson in an essay on 'The Memory of the Present' (Bergson 2002 [1908]). The notion of free indirect discourse has been mobilised to a limited extent by Deleuze's commentators in film studies (see Rodowick 1997: 61-2), but its radical potential has been missed inasmuch as it has not been connected to three syntheses which, from Difference and Repetition (1968) on, form the core of Deleuze's thought. By suggesting specific relationships between subjective and objective points of view in cinema, and between the camera and characters in films, Deleuze effectively draws a map of the way the spectator works with cinematic images and sounds.

In Deleuze's Cinema books, there are myriad categories of filmic aesthetics, affects and signs, but what is necessary for these categories to be possible is an underlying assumption of the ways in which films are watched. As Christian Metz astutely pointed out, in a different context, what is commonly referred to as the 'spectator' in film theory is, for the most part, something merely constructed by 'the imagination of the analyst' of any film. (He additionally points out that many analystspectators must also construct imaginary authors too, an observation that clearly holds true for Deleuze's analyses (Metz 1991: 760).) To construct the kinds of categories he does, then, Deleuze must have a notion of spectatorship which he uses to organise his writings on cinema.

As Deleuze and Guattari demonstrate in What is Philosophy?, the Cogito is a presupposition: it functions in thought as that which comes before thought. Deleuze's notion of a Cogito of art bears this out. $\mathrm{He}$ means that there are subjective and objective dimensions of experience: an empirical subject cannot exist without its transcendental correlate, and neither can a subject act without being doubled by a supposedly 'watching' subject that monitors those actions (the division is indebted to Kant's division between concepts and intuitions). The empirical subject acts automatically, as if they were being drawn along by their experiences, while the transcendental aspect of the subject 'sits back' and observes, monitors or watches the automatic, empirical aspect of the subject. ${ }^{1}$ This is how Deleuze presupposes cinema spectatorship works: spectatorship in the cinema is always doubled, such that there is a dividing-in-two of the cinematic experience, so that one part of the spectator receives and responds to images automatically, while another aspect of the spectator monitors these automatic responses. On the one hand, then, there is a part of the subject that is empirical-automatic, and this aspect of the spectator is guided by the bodily senses - this 


\section{Richard Rushton}

part of the spectator is embodied. On the other hand, there is a quasi intellectual or semi self-reflective aspect of the spectator, a transcendental part of subjectivity which searches for the conditions of possibility of any occurrence or act. ${ }^{2}$ If the empirical-bodily aspect of the spectator responds mechanically and automatically then it is the task of the transcendental-intellectual aspect of the spectator to enquire into the conditions which make possible the bodily reaction.

This is where the first cracks in Hansen's reading of Deleuze can be found: Hansen works only with the first dimension of the spectator in Deleuze, the empirical or bodily aspect. And, yes, here one can certainly argue that the empirical-bodily spectator is, in a sense, ruled by the images presented to it: the empirical-bodily spectator responds automatically and mechanically - and at the same time viscerally and physiologically - to the image. Perhaps these might be called subjective images. But it is a very strange kind of subjectivity, a subjectivity with no background or backdrop, and a subjectivity that lives entirely in the present, as it were, reacting and responding only to filmic events as they happen. If these are subjective images, then they are certainly not images guided by a subject. Rather, they are the responses of a subject that has lost all subjecthood, that has lost the traits of agency and selfdetermination. So it may be a strange thing indeed to call these subjective images, for they are images without a subject produced entirely by the filmic object. It is on this level, then, that Hansen's understanding of Deleuze's cinema spectator might be correct: a spectator-subject wholly guided by the objects presented to it.

An example can help to clarify these issues. A major point of reference in Deleuze's discussion of subjective and objective perceptions in the cinema is Jean Mitry's Aesthetics and Psychology of the Cinema (1963). There Mitry evocatively claims that 'In the cinema ... so-called subjective impressions are presented to me - as is everything else: the camera moves down the street, I move with it; it climbs the stairs, I climb with it. I thereby directly experience the sensations of walking and climbing (at least this is my impression)' (Mitry 1997: 210). These are clearly subjective images, as Mitry acknowledges, images that seem to emanate from the point-of-view of a subject. Yet, as he further notes, if these are considered subjective images, then they are not images that are produced by a subject:

Yet the camera is leading me, guiding me; it conveys impressions not generated by me. Moreover, the feet climbing the stairs I can see in the frame of the image are not mine; the hand holding onto the banister is not mine. 
At no point am I able to recognize the image of my own body. Thus it is obviously not me climbing the stairs and acting like this, even though I am feeling sensations similar to those I might feel if I were climbing the stairs. (Mitry 1997: 210)

Mitry therefore throws the notion of subjective images into question (he ultimately comes up with a category he calls the 'semi-subjective'): even though such images appear to be those of a subject and I as a spectator appear to be experiencing those shots subjectively, i.e., from a subjective point-of-view, such subjective shots are always necessarily determined by the camera. In fact, such shots are wholly determined by the camera: any subjectivity that I may experience in respect of what I see on the screen is imposed on me by the camera - all I can do is receive it. In this way, so-called subjective shots in the cinema are wholly determined by the cinematic object: they are objective images imposed on a spectatorsubject. These are subjective shots - 'so-called subjective impressions', as Mitry remarks - but they have the taste of objectivity: the most seemingly subjective shots of the cinema are those that are dictated to me and which I cannot in any way change or interact with.

In this situation, the body of the spectator-subject is 'acted' (as Bergson says) rather than 'active'. The stakes of Hansen's criticisms of Deleuze are pertinent, even valid, if one restricts one's view of cinema to what is presented here by so-called subjective images. And Mitry, if confined to this one example, provides us with Hansen's view of the cinematic experience: at all times I am guided by the camera; I cannot affect or effect the presentations I see there, and my body cannot participate in or interact with the images that are dictated to me by the screen; at the cinema I am merely a passive receptacle. And there is no question that such a conception of the cinematic experience does exist for Deleuze, but such a conception gives us only half the story, the half of the story in which the spectator can be regarded as 'empirical'. It is this part of the subject which receives impressions imposed on it by the cinematic apparatus: automatic, mechanical, properly receptive in the Kantian sense. These images can be described as subjective ones, but the kinds of subjectivity they offer are not ones produced by a subject. And ultimately, this seems to be why Hansen has such a problem with this kind of cinematic engagement: it amounts to a denial of subjectivity, a foreclosure of the possible activities of the subject, an abandonment of subjecthood. Cinematic subjectivity is here merely a kind of subjectivity that is at the mercy of cinema's apparatus: the screen, camera, projector, loudspeakers, and so on. 


\section{A Transcendental Spectator}

There is another dimension to the cinema spectator for Deleuze: the transcendental aspect, that which for Deleuze is associated with the potential for objective perception in the cinema. The best definition of an objective perception in the cinema is, for Deleuze, a negative one: an objective shot is one that is not subjective, which is to say, one that is not from a particular character's point of view. 'We should be able to say, in fact', writes Deleuze, 'that the image is objective when the thing or the set are seen from the viewpoint of someone who remains external to that set' (Deleuze 1986: 71). This, then, is the first point to take on board: it is extremely difficult to isolate objective images or shots. Rather, any sense of objectivity can only arise from the relations between different shots. It is a matter of finding or designating the conditions by means of which certain shots can be read and interpreted or understood: this is the transcendental aspect. Again Deleuze shows his debt to Kant, for by 'transcendental' Deleuze means the conditions of possible experience, the conditions which allow something to be experienced as an experience. And these are precisely the kinds of questions that the transcendental aspect of the spectator asks: 'Why is this happening?' 'Why did this occur?' and so on. There is, however, a significant difference between Kant's approach to the transcendental and Deleuze's. Kant grants transcendental authority to the active processes of the faculty of understanding (which faculty thus overrides the passive receptions of empirical intuition) whereas, for Deleuze, transcendental processes remain wholly passive: they are not the result of subjective effort. Rather, they emerge without the active or conscious provocation of the subject. In other words, these transcendental conditions happen to the subject rather than being caused by the subject.

There are objective shots in the cinema, but any quest for objectivity, from the spectator's point-of-view, is accompanied by a transcendental reflection - to reiterate Deleuze's claim noted earlier: 'an empirical subject cannot be born into the world without simultaneously being reflected in a transcendental subject' (Deleuze 1986: 73). If we think about the possibility of objectivity in the cinema in association with this transcendental aspect of the spectator, what will we find? Edward Branigan has very convincingly pointed out the necessity of a seemingly objective relation to filmic events. When watching films, Branigan argues, a spectator continually makes theoretical leaps between different occurrences in the narrative and constructs vague hypotheses about what will happen or what may have happened in order to convey upon the filmic material some sense of structure or organisation. That is, the 
spectator tries to put the pieces of a film together in order that the events of the film conform to some sort of potentially objective system. When a spectator engages in such an activity, then this activity, Branigan argues:

represents a hypothesis ... we are making about our perception of the world of the characters as we understand that world by apparently being in it; that is we are perceiving the world of the characters through projecting and imagining a situation in the diegesis whereby declarative knowledge of the relevant kind could be obtained and a description produced. (Branigan 1992: 165)

A film typically demands the construction of some kind of potentially objective diegetic world in which the events of the film are contained and unfold according to the expectations of that diegetic world. The assertions that, in a film, this happened, or that happened, can only be made in accordance with an objective, though hypothetical realm within which the events unfold. As Branigan puts it, 'This film's world as itself an object must be independent of certain angles of view' (Branigan 1992: 165). The film's world is defined by the specific shots (and editing patterns) of the film as they occur, but only insofar as these shots (or edits) are embedded in a world-as-object that the spectator puts together. The spectator constructs objective patterns within which the subjective material (the 'actions') of any film unfolds. This is what Deleuze means by 'transcendental': the conditions of possible experience, i.e., the conditions of possibility within which the events, actions, situations and contemplations of a film occur.

Branigan adds something more: he claims that if the spectator is intimating or inferring certain conditions of possibility, then that spectator makes these inferences on the basis of apparently being in this world. A fine example of this is provided in Max Ophuls' Letter from an Unknown Woman (1948). A young woman, Lisa, falls in love with a concert pianist, Stefan. It is a love from afar, however, as Stefan knows nothing of Lisa's passionate desire for him. One day, Lisa manages to sneak into Stefan's apartment when he is not at home, and she immediately makes her way to the piano which she has heard him play so often. Branigan concentrates on the two shots which chart Lisa's movements towards Stefan's piano. The first shot, a long shot from behind Lisa, shows her at quite some distance from the piano which is located in the background of the frame. The shot that immediately follows, this time from directly behind the piano, now shows Lisa standing right beside the piano. What occurs in the gap between these two shots? Do we, as spectators, infer that Lisa has somehow miraculously travelled twenty feet in an instant? Of course 


\section{Richard Rushton}

we do not! But we do, Branigan argues, fill in the missing time which the edit erases.

Our anticipation is an imaginary time attributable to Lisa's desire for Stefan through his piano. Fixated on the piano, she advances toward it, and the spectator completes the action; or rather, the spectator constructs a virtual time in which the action is realized. (Branigan, 1992: 182)

This simple example of two shots can clearly demonstrate the difference between the empirical and the transcendental aspects of the spectator from a Deleuzian point of view. On the one hand, that which enables the spectator to discern that the second shot occurs after the first one is empirical: our ability to infer a direction to time from one event to another, from the past to the future via the present, is a function of what Deleuze calls 'the passive synthesis of habit' in Difference and Repetition (Deleuze1994: 70-9), the first of the three syntheses of time which are central to Deleuze's philosophy. Derived as it is from notions of Kantian intuition (though Deleuze's most explicit reference is to Hume), the first synthesis enables us to situate events 'in' time. We intuit that an edit designates a flow of time and that during the time of this edit Lisa has crossed the room (there is certainly no sense in which these scene, with its potentially strange cut, is in any way difficult to understand).

But there is another dimension at work here. As Branigan suggests, there is 'an imaginary time attributable to Lisa's desire for Stefan through his piano' (Branigan 1992: 182). There are a whole series of conditions that make possible a deeper understanding of this filmic situation. The relation between the two shots could be said to be motivated by Lisa's desire - which is to say that these shots are, more or less, motivated by everything in the film that has preceded them. Our remembering of Lisa's unrequited love for Stefan and our knowledge of her many attempts and sacrifices made to be close to him, give Lisa's movement from the first shot to the next an added depth. In Deleuzian terms, this is a function, for the spectator, of the 'second passive synthesis of memory': the motioning towards the conditions of possibility of any event based upon our past experiences; the present can only function as 'present' on the basis of a past which conditions it as present (Deleuze 1994: 79-88). These are, then, as they are for Kant, transcendental conditions.

What, then, may be said of the subjective and objective aspects of the spectator? The empirical dimension of the spectator is not necessarily as subjective as it might at first appear, so does this mean that the transcendental side of the spectator is likewise not necessarily objective? 
The transcendental conditions that make possible the relation between these two shots - conditions like our knowledge of Lisa's unrequited desire for Stefan - could be said to be objective insofar as one would have great difficulty understanding the film without such conditions. But if by objective one means elements of the film that are put in place by the film itself without the input of the spectator - that is, things in the film that are not determined by the subjects who experience this film - then the claim for objectivity cannot hold. As Branigan claims, 'the spectator completes the action; or rather, the spectator constructs a virtual time in which the action is realized' (Branigan 1992: 182). ${ }^{3}$

The transcendental spectator-subject of the cinema is crucially subjective, even if it is this aspect which offers an objective dimension of spectatorship. These are the images or concepts of a film that simply would not exist were it not for the fact that there is someone to watch, listen to and make sense of them. It is nothing less than what the spectator, at any point during the viewing of a film, adds to that film. This is manifestly a transcendental level of understanding: what a subject adds to the viewing experience in order to grant that experience a potential objectivity.

It is not merely the preceding events of a film itself that add to this transcendental level of understanding, but rather, as Deleuze would have it, the whole of one's past. ${ }^{4}$ This is not as mysterious as it may at first sound, for what can it be that makes Letter from an Unknown Woman so romantic and compelling for many viewers? Surely one reason, an important one, is that many viewers of the film have loved from afar and thus share a deep sympathy for the situation Lisa finds herself in. One might even go so far as to say that an element of personal, deeply subjective memory might, for the spectator, be said to infuse itself with the past of the film and that it is only on the basis of such pasts that the film could be said to be enjoyable, engaging or memorable for any spectator (conversely, an absence of such memories might amount to making the film entirely uninteresting for a spectator).

Would not this then be a very important form of interaction for the spectator? Indeed, that which makes a film a film requires an enormous amount to be given to the film by the spectator-subject. The spectactorsubject is, as Metz put it, a midwife to the image:

I'm at the cinema. I am present at the screening of the film. I am present. Like the midwife attending a birth who, simply by her presence, assists the woman in labour, I am present for the film in a double capacity (though they really are one and the same) as witness and as assistant: I watch, and I help. By 


\section{Richard Rushton}

watching the film I help it to be born, I help it to live, since only in me will it live, and since it is made for that purpose: to be watched. (Metz 1982: 93)

\section{Passions and Actions}

For Hansen to claim that the cinema spectator cannot interact with films - to imply that the spectator at the cinema is simply at the mercy of the filmic object and automatically plays along to its tune, and that Deleuze's cinema spectator is therefore merely 'the passive correlate of linkages between images' (Hansen, 2004a: 7) - is to grossly underestimate the input the spectator necessarily makes to the unfolding of any film. ${ }^{5}$ And yet, such a spectator is not at the same time necessarily active, for all of the activities I have been describing by way of Deleuze as transcendental are, at their foundation, passive. ${ }^{6}$ The kind of experience of monitoring or recollecting that Deleuze attributes to the transcendental passive synthesis of memory is one that happens to us and which affects us, but without our necessarily consciously knowing it, and certainly without our consciously activating it.

Again, the passivity of Deleuze's cinema spectator can be compared with the active new media spectator theorised by Hansen. Hansen argues, for example, that Douglas Gordon's post-cinematic works, such as 24-Hour Psycho (1993), offer a 'refinement' of the sensorimotor processes of classical cinema:

Unlike the sensorimotor interval at work in the cinema of the movementimage, this refined sensorimotor interval [as exemplified by Gordon's works] is not immanent to the logic of the image or of film as the art of moving images, but emerges directly from the human processing of information. Consequently, it is a sensorimotor interval that taps the potential of the body to exceed its own contracted habits and rhythms. (Hansen 2004a: 246-8)

In this case, then, the body asserts its activeness, an activity that emerges 'directly' (for reasons which are very unclear to me) 'from the human processing of information', over and against what must be an inherently inactive new media image. The body exceeds its own limits as a result of its own activity and thus the origin of the new media object lies in the empowerment it offers to the spectator-subject. I make the new media world in the image of my own excess: 'it is the viewer's body in itself (and no longer as an echo of the work's "content")', argues Hansen, 'that furnishes the site for the experience of [new media] "works"” (Hansen 2004a: 31). For Deleuze, on the other hand, the cinematic sensorimotor subject does not simply impose itself on the world in a mode of mastery, but rather acknowledges the necessity of negotiating 
with the world and its objects - including cinematic ones - in the hope of being able to 'reconnect man to what he sees and hears' (Deleuze 1989: 172). This subject is not one who is isolated from the world, cocooned in a subjectivity that it continually tries to assert over the world, but is rather part of a world with which it is in continual symbiosis.

Hansen's attempt to theorise new media in terms of our responses to it, rather than theorise its objects, necessitates a notion of subjectivity that actively creates or contributes to the very objects of new media: 'the [new media] image does not comprise a representation of a preexistent and independent reality, but rather a means for the new media user to intervene in the production of the "real", now understood as a rendering of data' (Hansen 1994: 10). Because of this, 'the [new media] "image" itself has become a process and, as such, irreducibly bound up with the activity of the body' (Hansen, 1994: 10). Thus, the new media image does not exist without the bodily affects that are added to it by the spectator-participant. As a result, the new media image may be considered fundamentally interactive and therefore a process more than a product inasmuch as the spectator-participant's activity is crucial to the object's creation and existence.

Against this conception of the spectator's interactivity with new media, Hansen posits the 'old' cinematic medium as one of immobility, passivity, and non-interactivity (Hansen 2004a: 34). His chief target in conceptualising the oldness of the cinematic medium is, as we've seen, Deleuze, who, according to Hansen's reading, 'cannot account for the primacy of the subjective dimension of the body' (Hansen 2004a: 194). For Hansen, Deleuze's conception of cinema is one that aims to 'disembody the center of indetermination [by which Hansen, borrowing from Bergson, means 'human'] and thus free cinema to operate an “inhuman” perception' (Hansen 2004a: 70). According to Hansen, then, Deleuze erases all embodiment from human subjects. As we've seen, this is clearly not the case for Deleuze, for whom the body and bodily processes of the to-ing and fro-ing of the empirical and transcendental aspects of the spectator are fundamental to the conception of the cinematic experience.

Hansen also charges that Deleuze erases the subjective dimension of the body, thus bringing about the conditions of an inhumanity. Again, as we've seen, it must be remembered that so-called subjective experiences in cinema are never caused by subjects. Rather, they are subjectivities which happen to subjects and which thus help to create those subjects as processes. Hansen, it seems to me, regards subjects or subjective bodies as agents: as the active causes of the processes which create both 


\section{Richard Rushton}

new media objects, and by extension, their own subjectivities. Hansen's conception may thus be seen as an embodied, and hence inverted, version of the Cartesian Cogito ('I affect, I am') as distinct from Bergson's or Deleuze's complex Cogito.

Against Hansen's reification of the embodied subject, Deleuze's conception of subjectivities - and these are subjectivities fundamental to the cinematic experience - is one that posits them as composites of subject and object in states of deformation and reformation which respond to and act upon the fluctuations of empirical reception and transcendental structuration. Against notions of 'the subject', Deleuze declared a preference for terms such as pre-individual singularities or non-personal individuations (Deleuze 2006: 351). Such individuations are inhuman only insofar as they reject notions of isolated, self-created and self-creating subjects who are masters of all they affect. For Deleuze, 'Underneath the self which acts are little selves which contemplate and which render possible both the action and the active subject' (Deleuze 1994: 75).

\section{Clarifications}

Hansen's new media spectator adds two things to the new media object (and these properties are those which make new media objects 'new' for Hansen): affection and a virtualisation of the body. These concepts are, for Hansen, reversals of Deleuze's cinematic notions of affection (or 'affection-image') and the virtual. Hansen grants the powers of affection and the virtual to the body of the subject, whereas (on Hansen's reading) Deleuze makes objects the seat of affection and the virtual. ${ }^{7}$

On affection, Bergson (from whom Deleuze and Hansen borrow liberally) does indeed claim that 'my perception is outside my body and my affection within it' (Bergson 1988: 57). Deleuze confirms this view when he writes that affection is the way the subject 'experiences itself or feels itself "from the inside" (Deleuze 1986: 65). Bergson also goes on to argue, in Matter and Memory, that 'Affection is, then, that part or aspect of the inside of my body which we mix with the image of external bodies' (Bergson 1988: 58). And again it seems that Deleuze agrees with Bergson that affection is 'a coincidence of subject and object' (Deleuze 1986: 65). No clear division is made here between subject and object, for affection is a mixture or conjunction of the two. In his book on Bergsonism, Deleuze even states that, as fundamental to his project, 'Bergson shows how the lines of objectivity and subjectivity, the lines of external observation and internal experience must converge at the 
end of their different processes' (Deleuze 1991: 30). The all-too-clear divisions between subject and object that Hansen relies upon are clearly non-existent.

As for the notion of the virtualisation of the body, Hansen relies on the same strict division between subject and object. Whereas the virtual image in cinema consists of something 'emanating from the image itself' (Hansen 2004a: 215) - that is, from its objects - the virtualities of new media objects are 'not images of empirical spaces' (Hansen 2004a: 214); they are not virtualities that emerge from outside the body; rather, they function as catalysts for the virtualisation of the body. Thus, they are the provenance of subjects (Hansen, 2004a: 214). Hansen's subjects are endowed with sovereignty, while it is claimed that Deleuze gives everything over to the cinema's objects. Such a view flies directly in the face of Deleuze's explicit statement that in cinema 'The actual is always objective, but the virtual is subjective' (Deleuze, 1989: 83). ${ }^{8}$ What Deleuze here means by the virtual can be placed alongside his formulation of the transcendental in cinema: the transcendental conditions of experience are virtual; they are evocations of the past and, as such, are not actual. Certainly these designations are not straightforward: the virtual 'preserves the past' (Deleuze 2002: 151) but can also be actualised in the present. At the limit, the virtual and the actual become indistinguishable (for the cinema, this is what Deleuze calls the time-image), though such indistinguishability only ever occurs 'inside someone's head', as Deleuze puts it (Deleuze 1989: 69). And furthermore, the virtual is primarily passive, inasmuch as it is never a product of consciousness, and not active (an active summoning up of one's past is what Deleuze calls the 'recollection-image', whereas the form of memory which corresponds to a passive instantiation of the virtual is designated, after Bergson, pure recollection (Deleuze 1989: 79-80). The virtual is not produced by consciousness, but instead produces consciousness. It is therefore subjective, but it is a subjectivity that happens to the subject rather than one that is caused by the subject, 'the affection of a passive self which experiences its own thought' (Deleuze 1994: 86).

Finally, I have mentioned in detail only two of the three syntheses Deleuze theorises in Difference and Repetition. There is a good reason for this: I believe the third synthesis (Deleuze 1994: 88-91), is chiefly important for the spectator of modern cinema, that is, for the spectator of the time-image who discovers 'a little time in the pure state' (Deleuze 1989: 169). Insofar as Deleuze characterises the third synthesis as 'the empty form of time' or the 'pure order of time' (Deleuze 1994: 88 ), then the connections to be made between the third synthesis and 


\section{Richard Rushton}

the time-image are certainly suggestive. The time-image, as much as the third synthesis, occurs when the past returns as a disruption which realigns past, present and future. It is also the point at which any sense of subjectivity it pushed to its limits and produces a 'man without a name, without family, without qualities, without self or I' (Deleuze 1994: 90). 'In the third synthesis', writes Deleuze, 'the present is no more than an actor, an author, an agent destined to be effaced' (Deleuze 1994: 94).

\section{References}

Bergson, Henri (1988 [1896]) Matter and Memory, trans. Nancy Margaret Paul and W. Scott Palmer, New York: Zone Books.

Bergson, Henri (2002 [1908]) 'Memory of the Present and False Recognition', in Keith Ansell Pearson and John Mullarkey (eds) Bergson: Key Writings, New York and London: Continuum, pp. 141-56.

Branigan, Edward (1984) Point of View in the Cinema: A Theory of Narration and Subjectivity in Classical Film, Berlin, New York and Amsterdam: Mouton.

Branigan, Edward (1992) Narrative Comprehension and Film, New York and London: Routledge.

Casetti, Francesco (1998) Inside the Gaze: The Fiction Film and its Spectator, trans. Nell Andrew with Charles O'Brien, Bloomington and Indianapolis: Indiana University Press.

Deleuze, Gilles (1983 [1962]) Nietzsche and Philosophy, trans. Hugh Tomlinson, London: Athlone.

Deleuze, Gilles (1986 [1983]) Cinema 1: The Movement-Image, trans. Hugh Tomlinson and Barbara Habberjam, London: Athlone.

Deleuze, Gilles (1989 [1985]) Cinema 2: The Time-Image, trans. Hugh Tomlinson and Robert Galeta, London: Athlone.

Deleuze, Gilles (1991) Bergsonism, trans. Hugh Tomlinson and Barbara Habberjam, New York: Zone Books.

Deleuze, Gilles (1994 [1968]) Difference and Repetition, trans. Paul Patton, London: Athlone.

Deleuze, Gilles (2002) 'The Actual and the Virtual', in Dialogues II, London: Athlone, pp. 148-52.

Deleuze, Gilles (2006) 'Response to a Question of the Subject', in Two Regimes of Madness: Texts and Interviews, 1975-1995, New York, NY: Semiotexte, pp. 349-51.

Deleuze, Gilles and Guattari, Félix (1994) What is Philosophy?, trans. Graeme Burchell and Hugh Tomlinson, New York and London: Verso.

Hansen, Mark. B. N. (2004a) New Philosophy for New Media, Cambridge, MA, and London: MIT Press.

Hansen, Mark. B. N. (2004b) 'Communication as Interface or Information Exchange? A Reply to Richard Rushton', Journal of Visual Culture, 3: 3, pp. 359-66.

Metz, Christian (1982) 'Story/Discourse (A Note on Two Kinds of Voyeurism)', in Psychoanalysis and Cinema: The Imaginary Signifier, trans. Celia. Britton, Annwyl Willims, Ben Brewster and Alfred Guzzetti London: Macmillan, pp. 91-8.

Metz, Christian (1991) 'The Impersonal Enunciation, or the Site of Film (In the margin of some recent works on enunciation in cinema)', New Literary History $22: 3$, pp. 747-72. 
Mitry, Jean (1997 [1963]) The Aesthetics and Psychology of the Cinema (abridged), trans. Christopher King. Bloomington and Indianapolis: Indiana University Press.

Olkowski, Dorothea (1999) Gilles Deleuze and the Ruin of Representation, Berkeley, Los Angeles and London: University of California Press.

Pisters, Patricia (2003) The Matrix of Visual Culture: Working with Deleuze in Film Theory, Stanford: Stanford University Press.

Rodowick, D. N. (1997) Gilles Deleuze's Time Machine, Durham and London: Duke University Press.

Rushton, Richard (2004) 'Response to Mark B.N. Hansen's “Affect as Medium, or the 'Digital-Facial-Image' "', Journal of Visual Culture, 3: 3, pp. 353-8.

\section{Notes}

1. These ideas are quite explicitly taken from Bergson: 'a compenetration of states which melt into one another and even coincide in immediate consciousness will represent them by a duplication of the self into two different personages, one of which appropriates freedom, the other necessity: the one, a free spectator, beholds the other automatically playing his part' (Bergson, 2002: 149).

2. The division between the intellect and the body is an artificial one insofar as Deleuze does not theorise any division between the two. He states, rather, that sensations are formed by 'contemplation' for example (see Deleuze 1994: 70-75), and (writing with Félix Guattari) that 'Sensation is no less brain than the concept' (Deleuze and Guattari 1994: 211), while sensations and concepts make up the 'first two aspects or layers of the brain-subject' (Deleuze and Guattari 1994: 213)

3. It is worth noting that much of Branigan's discussion refers to notions unpacked in great detail in his Point of View in the Cinema where, for example, he outlines his 'reading hypothesis theory': 'According to a reading hypothesis theory, then, the camera is not a profilmic object which is shifted from place to place, but a construct of the spectator, a hypothesis about space - about the production and change of space' (Branigan 1984: 54).

4. As Deleuze asks, 'The entire past is conserved in itself, but how can we save it for ourselves? (1994: 84). Also see Deleuze's comments on the famous cone diagram from Bergson's Matter and Memory (Deleuze 1989: 294, n. 22).

5. See, for example, Francesco Casetti's discussion of cinema as 'interface' (Casetti, 1998: 129-30).

6. This passivity of the spectator can, from another point of view, be compared with the 'reactivity' of forces Deleuze finds in Nietzsche. As for reactive forces, any spectatorial passivity should follow the dictum to go to 'the limit of its consequences' (See Deleuze 1962: 66).

7. For a more detailed discussion of these issues see Rushton (2004) and Hansen's response $(2004 b)$.

8. Deleuze's full statement of the issue is thus: 'Subjectivity is never ours, it is time, that is, the soul or the spirit, the virtual. The actual is always objective, but the virtual is subjective: it was initially the affect, that which we experience in time; then time itself, pure virtuality which divides itself in two as affector and affected, "the affection of self by self" as definition of time' (Deleuze 1989: 82-3). 